\title{
The ABCs of Sleep Apnea Management
}

\author{
Cecilia Turino', Manuel Sánchez-de-la-Torre ${ }^{1,2}$ and Ferran Barbé $e^{1,2}$
}

${ }^{1}$ Respiratory Department, Hospital Universitari Arnau de Vilanova and Santa Maria, IRB Lleida, Lleida, Catalonia, Spain; ${ }^{2}$ Centro de Investigacion Biomédica

en Red de Enfermedades Respiratorias (CIBERES), Madrid, Spain

\section{ABSTRACT}

Obstructive sleep apnea is a chronic disorder that is defined by the presence of recurrent episodes of upper airway collapse during sleep, resulting in nocturnal hypoxemia and sleep fragmentation. Upper airway collapse has been related to genioglossus activity, high loop gain, rostral fluid shift, and arousal threshold. Obstructive sleep apnea affects 10\% of adult men and 3\% of adult women. However, its prevalence is expected to rise due to the aging population and an increased obesity rate, both of which are related to obstructive sleep apnea development. Obstructive sleep apnea does not target a single organ but, if left untreated, it is a risk factor for arterial hypertension, cardiovascular and cerebrovascular diseases, a worse quality of life, and, likely, cancer. Full-night polysomnography is considered the gold standard in diagnosing obstructive sleep apnea and other sleep disorders, but home testing with portable monitors is a suitable alternative for evaluating patients with high or moderate clinical suspicion for obstructive sleep apnea and without comorbidities. Treatment choice depends on severity and symptoms. Continuous positive airway pressure is the primary treatment in severe obstructive sleep apnea. No clear evidence has supported the recommendation of continuous positive airway pressure treatment in patients with mild-to-moderate obstructive sleep apnea and alternative treatments could be used in these patients. Effective diagnosis and treatment are critical in preventing obstructive sleep apnea-related complications. Nurses and general practitioners should be involved in the management of obstructive sleep apnea patients. In this review, we aim to provide basic information about the risk factors, clinical presentation, and treatment of obstructive sleep apnea and to increase familiarity with the disease. (BRN Rev. 2015;1:48-61) Corresponding author: Ferran Barbé, febarbe.lleida.ics@gencat.cat

Key words: Adherence. Cardiovascular risk. CPAP. OSA. 


\section{INTRODUCTION}

Obstructive sleep apnea (OSA) is defined by the presence of recurrent episodes of upper airway collapse during sleep, resulting in nocturnal hypoxemia and sleep fragmentation (Table 1). The associated daytime sleepiness could lead to an increased risk of motor vehicle and occupational accidents, as well as a reduced quality of life ${ }^{1-3}$. Furthermore, the intermittent hypoxemia, arousals, and changes in thoracic pressure from repetitive airway obstructions predispose OSA patients to atherosclerosis $^{4,5}$. The primary mechanisms that link OSA to atherosclerosis are oxidative stress and sympathetic activation. If left untreated, OSA results in a higher risk of arterial hypertension, cardiovascular and cerebrovascular diseases ${ }^{6}$ and, likely, cancer ${ }^{7}$. In Western countries, OSA occurs in $10 \%$ of middle-aged men and $3 \%$ of middle-aged women, but its prevalence is expected to increase because of its strong association with obesity and age ${ }^{8}$.

\section{CAUSES AND CONSEQUENCES OF OBSTRUCTIVE SLEEP APNEA}

Obstructive sleep apnea is caused by an increased collapsibility of the upper airway. In the area localized between the hard palate and larynx, the absence of a rigid support system, such as cartilage or bone, make tissues prone to collapse. Upper airway patency exclusively depends on a balance between the forces that are inclined to close airways (e.g. intraluminal and extraluminal pressure, pharyngeal wall compliance, and neck circumference) and the forces that are inclined to open airways (e.g. dilator muscle activity). Genioglossus is the most important airway dilator
TABLE 1. Definitions and terminology

Apnea: the absence or reduction by at least $90 \%$ of breathing with minimum 10 seconds duration.

Hypopnea: a reduction (30 or $50 \%$ ) in respiratory flow with either 3 or $4 \%$ desaturation or an arousal from sleep.

AHI: number of apneas and hypopneas per hour of sleep.

OSA syndrome: $\mathrm{AHI} \geq 5$ + symptoms (daytime sleepiness, loud snoring, witnessed breathing interruptions, or awakenings due to gasping or chocking).

Positional OSA: a doubling in the number of apneas/hypopneas in the supine compared with the lateral position.

Mild OSA: $A H I \geq 5$ but $<15$.

Moderate OSA: $\mathrm{AHI} \geq 15$ but $<30$.

Severe OSA: $A H I \geq 30$

OSA: obstructive sleep apnea; AHI: apnea/hypopnea index. Adapted from The AASM Manual for the Scoring of Sleep and Associated Events, 2007.

muscle. Its activity increases during deep sleep and reduces during transition to sleep in both OSA patients and healthy subjects? However, in OSA, decreased input from the central respiratory system, impaired muscle mechanoreceptor activities and chemoreceptors, and a low arousal threshold could negatively influence the dilator activity of genioglossus and cause airway collapse ${ }^{9}$. Sleep arousal is the principal mechanism restoring airway patency during apneas or hypopneas. The term "loop gain" is used to express the tendency toward respiratory system instability in response to a breathing perturbation. The respiratory response to hypoxemia or hypercapnia (controller gain), the ability to eliminate $\mathrm{CO}_{2}$ or to store $\mathrm{O}_{2}$ (plant gain) and circulation time (mixing gain) regulate loop gain. The OSA patients have high loop gain, that is an altered central respiratory pattern generator, with increased respiratory rhythm oscillation and an extreme ventilatory response to arousals. Both mechanisms, through 


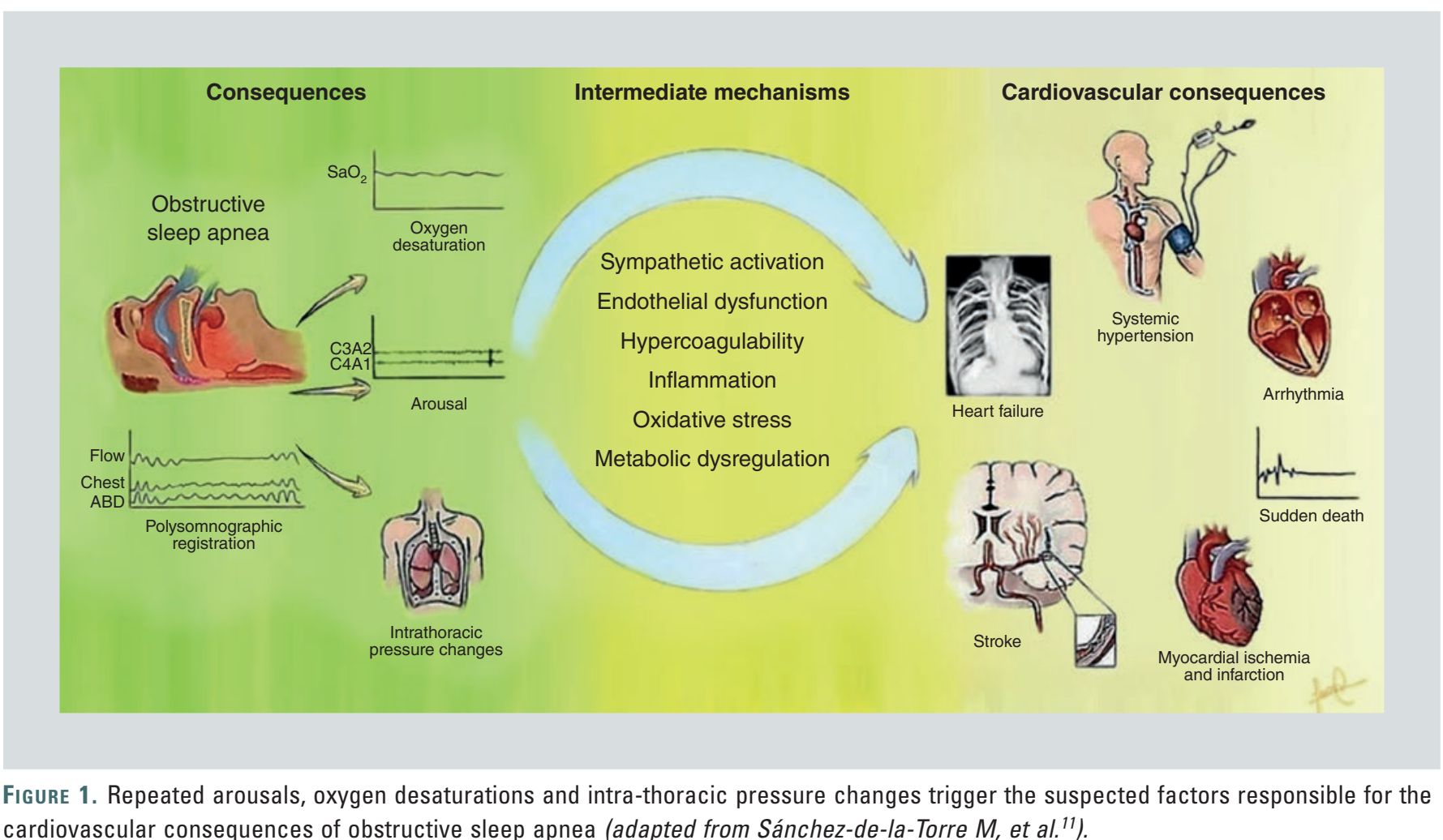
cardiovascular consequences of obstructive sleep apnea (adapted from Sánchez-de-la-Torre M, et al. ${ }^{11}$ ).

hyperventilation, could induce cyclic breathing and promote OSA development ${ }^{9}$.

The observation that the prevalence of OSA is high in patients with fluid retention, such as end-stage renal disease or heart failure, has lead to the formulation of "the rostral fluid shift theory"10. During the day, corporal fluids accumulate in the legs due to gravity, whereas in the supine position, fluids redistribute and accumulate in the neck and upper airway. Magnetic resonance imaging has been used to document pharyngeal mucosal edema in OSA patients, along with increased cross-sectional area and pressure in the internal jugular vein when lying down, which distributes throughout the pharynx wall. In this manner, extraluminal pressure in the pharynx increases, eventually exceeding the intraluminal pressure and leading to upper airway collapse. Repeated arousals, oxygen desaturations, and intrathoracic pressure changes trigger the pathologic mechanisms ${ }^{11}$ responsible for the cardiovascular consequences of OSA (Fig. 1). Increased sympathetic activity, demonstrated while awake and asleep, may predispose patients to systemic hypertension. The sympathetic activity and elevated oxidative stress observed in OSA could induce endothelial dysfunction and contribute to atherosclerosis and cardiovascular disease development. In addition, augmented plasma fibrinogen levels, blood viscosity and increased platelet aggregation could be responsible for the development of thrombosis disease. Frequently, OSA is observed in patients affected by metabolic syndrome, and different metabolic alterations, such as increased free fatty acid 
concentration, insulin resistance, and dyslipidemia, have been attributed to OSA ${ }^{11}$. As shown previously, OSA is a complex condition that could have an important impact on health, and it is a risk factor for developing or worsening pre-existing diseases.

\section{CLINICAL CONDITIONS RELATED TO OBSTRUCTIVE SLEEP APNEA}

As a part of a routine health maintenance evaluation, patients should be asked about their sleep quality and history of snoring and daytime sleepiness ${ }^{12}$. Patients at high risk of OSA should be studied. Obesity is the major risk factor for OSA, and among overweight/ obese adults (body mass index [BMI] $>25 \mathrm{~kg} /$ $\mathrm{m}^{2}, 30-69$ years old), excess weight appears to be responsible for $41 \%$ of all OSA cases and $58 \%$ of moderate-to-severe OSA cases ${ }^{13}$. Furthermore, the risk of OSA increases as the level of obesity increases: a 10\% weight gain is associated with a sixfold increase in the risk of developing moderate or severe OSA, and each $1 \%$ change in weight is associated with a 3\% change in the apnea-hypopnea index $(\mathrm{AHI})^{14}$. Among obese patients scheduled for bariatric surgery, OSA prevalence is estimated to exceed $70 \% 15$, and OSA patients undergoing surgery have a significantly greater risk of postoperative hypoxemic episodes, intensive care unit transfers, and longer hospital stays ${ }^{16}$. There is evidence that the perioperative treatment of OSA may reduce the incidence of postoperative complications ${ }^{17}$. Some authors have suggested evaluating subjects with a family history of OSA, retrognathia, type 2 diabetes, congestive heart failure, atrial fibrillation, nocturnal dysrhythmias, and stroke $^{12}$. An OSA evaluation may also benefit patients with resistant hypertension ${ }^{18}$. In fact, OSA is prevalent among patients with resistant hypertension $(>70 \%)$.

\section{QUESTIONNAIRES, SLEEP ANAMNESIS AND PHYSICAL EXAMINATIONS}

Among all screening questionnaires developed to assess the risk of OSA, two widely used and well-validated instruments are the Berlin and STOP-Bang questionnaires (Appendix 1 and 2). The Berlin Questionnaire asks patients about snoring, witnessed apneas, daytime sleepiness, obesity, and hypertension. Identifying two OSA risk categories (low and high), the instrument demonstrates $86 \%$ sensitivity and $77 \%$ specificity for predicting the presence of OSA among primary care patients ${ }^{19}$. The STOP-Bang questionnaire is composed of eight questions starting with the acronym STOP-Bang, and each positive answer is scored with one point. In perioperative settings, a score of $\geq 3$ has shown high sensitivity for detecting OSA, with sensitivities of 93 and $100 \%$ for moderate and severe OSA, respectively ${ }^{20,21}$. However, these questionnaires lose clinical utility when they are not used in the selected populations for whom they have been developed.

Snoring is the most sensitive symptom, but it is not specific. Conversely, nocturnal gasping or choking shows high specificity in detecting obstructive sleep apnea ${ }^{22}$. Excessive daytime sleepiness is also nonspecific, but it could be useful for outcome and severity assessment as well as for monitoring treatment respons$\mathrm{es}^{23-28}$. The Epworth Sleepiness Scale (ESS) (Appendix 3) is an eight-item questionnaire 


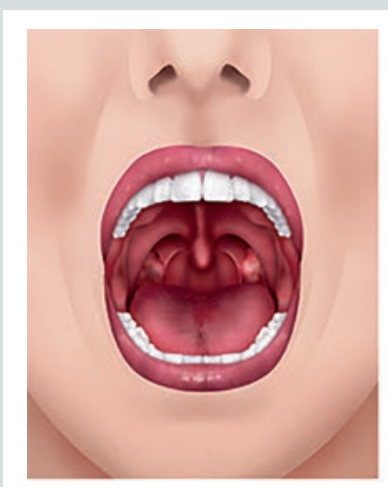

Mallampati I

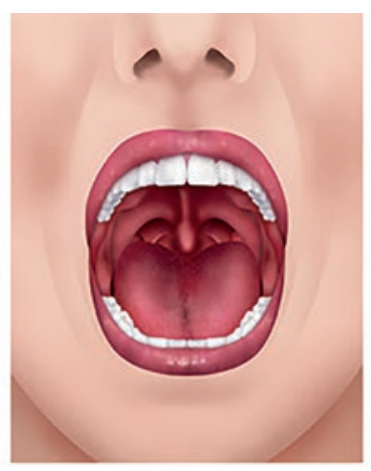

Mallampati II

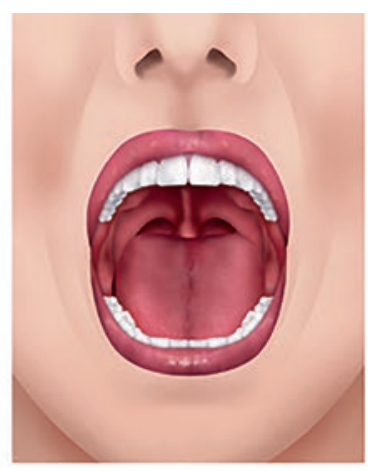

Mallampati III

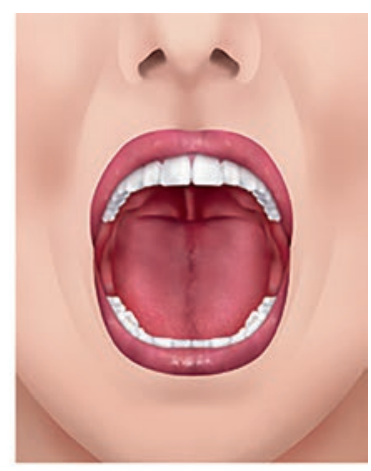

Mallampati IV

Figure 2. The Mallampati score (adapted from www.beverlyhillstmjheadachepain.com/sleep-apnea/diagnosing-sleep-apnea/mallampati-score/).

that assesses a patient's daytime sleepiness by scoring how likely he or she is to fall asleep or doze off during different daily life situations ${ }^{29}$. The main limitation of the ESS is its reliance upon the patient's self-perception of sleepiness rather than upon objective measurements. In patients with poor awareness of their own sleepiness, the ESS results may not be credi$\mathrm{ble}^{30}$. In some cases, a close relative who can observe a patient's daily life routines and note any episodes of dozing off or sleeping in these daily situations could assist in assessing the patients' daytime sleepiness ${ }^{31}$. The presence of nocturia, morning headaches, sleep fragmentation/maintenance insomnia, memory loss, and decreased libido, which are manifestations of untreated OSA, should be questioned $^{12}$. Comorbidities that are frequently associated with OSA, such as hypertension, stroke, ischemic heart disease, heart failure, or a history of motor vehicle accidents, should also be investigated.

Respiratory, cardiovascular and neurologic systems should be examined. In particular, the presence and degree of obesity should be evaluated; similarly, the presence of "obstruction features", such as enlarged neck circumference ( $>42 \mathrm{~cm}$ in women, $>43 \mathrm{~cm}$ in men), a modified Mallampati score of 3 or 4 (Fig. 2), retrognathia, lateral peritonsillar narrowing, macroglossia, tonsillar hypertrophy, an elongated/enlarged uvula, a high arched/narrow palate, nasal obstruction (for polyps, deviation, valve abnormalities, turbinate hypertrophy, congestion) and/or overjet, should be noted $^{12}$. Furthermore, some ocular clinical signs could give rise to a suspicion of OSA. Floppy eyelid syndrome is in fact associated to OSA in $85 \%$ of cases $^{32}$.

\section{DIAGNOSIS}

In-laboratory complete polysomnography (PSG) and home testing with portable monitors are the two accepted methods of diagnosing OSA. Full-night PSG is considered the gold standard in diagnosing OSA and other sleep disorders, but a split-night study (two hours of diagnostic study documenting OSA, followed by continuous positive air pressure titration) 
could serve as an alternative ${ }^{12}$. Home testing is a suitable alternative for evaluating patients with high or moderate clinical suspicion for OSA and without comorbidities (cardiopulmonary, neurological, other suspected sleep disorders) ${ }^{33}$. Symptomatic patients with negative or failed home testing should undergo standard polysomnography ${ }^{33}$.

Obstructive sleep apnea severity is expressed by the AHI, which is defined as the number of apnea (complete cessation of airflow for at least 10 seconds) and hypopnea (reduction of respiratory flow associated to a 3 or $4 \%$ oxyhemoglobin desaturation or arousal from sleep) episodes occurring per hour of sleep. The OSA severity is shown in table 1 . In addition to diagnosing and assessing OSA severity, sleep studies can supply information about the quality of sleep (e.g. total sleep time, sleep stages, sleep efficiency) and the presence of other abnormal respiratory patterns or sleep disorders (e.g. Cheyne-Stokes breathing, hypoventilation, periodic limb movements) and can identify parasomnias through video/audio recordings. Given the high prevalence of OSA, it appears crucial to involve general practitioners in its management. Modern technologies already allow OSA diagnoses and follow-ups in primary care settings, with encouraging early results ${ }^{34,35}$.

\section{OBSTRUCTIVE SLEEP APNEA TREATMENT}

Obstructive sleep apnea is a chronic condition that requires long-term multidisciplinary management, involving nurses and general practitioners. Furthermore, patients should play active roles in every phase of this process.

\section{Continuous positive airway pressure}

Continuous positive airway pressure (CPAP) is the primary treatment for severe OSA. Providing a pneumatic splint, a CPAP device prevents upper-airway collapse during sleep and has been shown to improve daytime sleepiness and oxygen saturation ${ }^{36}$, ameliorate neurobehavioral performance, improve quality of life, reduce road accidents, and reduce cardiovascular risk ${ }^{37-39}$.

\section{Who to treat?}

Patients with daytime sleepiness or a history of recent car crashes due to sleepiness, regardless of severity, should be recommended for CPAP treatment. In patients with $\mathrm{AHI}<30$, the presence of symptoms and cardiovascular risk factors should guide treatment decisions ${ }^{40-43}$. Sleepy patients appear to benefit from CPAP therapy more than non-sleepy patients, and CPAP treatment could improve driving performance and reduce crash rates ${ }^{44-46}$. Some authors have suggested that CPAP treatment in men with severe OSA (AHI > 30) could reduce the risk of fatal and non-fatal cardiovascular events ${ }^{47}$. Until now, no clear evidence has supported the recommendation of CPAP treatment in patients with mild-to-moderate OSA.

\section{Which continuous positive airway pressure? Continuous positive airway pressure titration}

A full-night, in-laboratory, complete polysomnography is the gold standard for CPAP titration. An automatic procedure (APAP) is a good alternative in patients without significant 
comorbidities (central sleep apnea syndromes, hypoventilation syndromes, chronic obstructive pulmonary disease, congestive heart failure), and it is more cost effective. Therapeutic pressures for OSA typically fluctuate between 4 and $20 \mathrm{~cm} \mathrm{H}_{2} \mathrm{O}$. Studies comparing fixed CPAP, APAP, and double-level pressure therapy in OSA have not shown differences in terms of residual AHI, improved quality of life, or decreased daytime sleepiness ${ }^{48-50}$.

\section{Mask choice and patient involvement}

Before starting therapy, patients should work with their care teams to select the most appropriate PAP interface. Patient comfort should guide the mask choice. Nasal masks and nasal pillows are more comfortable for patients with claustrophobia. Nasal pillows could also be considered in patients with unusual facial anatomy that could complicate the application of conventional oronasal or nasal masks. For a patient who sleeps with his mouth open, an oronasal mask is recommended to prevent flow escape from the mouth and subsequent loss of splint effectiveness. After initiating therapy, the patients should be educated about the function, care, and maintenance of their device, as well as the benefits of therapy and possible adverse events ${ }^{12}$ (Fig. 3).

\section{Adherence}

Continuous positive airway pressure adherence is similar to any other chronic treatment. Use of CPAP devices for four or more hours per night on $70 \%$ of nights indicates adequate
CPAP adherence ${ }^{51}$. Patients will be instructed to bring their machines and masks to follow-up visits, and data concerning adherence to therapy should be downloaded from the internal clock of the device because patients tend to overestimate CPAP use. A relationship has been observed between the number of hours of CPAP use, reduced sleepiness, and 24-hour mean blood pressure and enhanced quality of life ${ }^{52,53}$. Strategies to improve CPAP adherence include bed partner support, cognitive behavioral strategies focused on CPAP, and support groups ${ }^{54}$. The CPAP adherence during the first week could predict long-term compliance, and patient adherence appears to be related to symptom improvement and comorbidities.

In case of CPAP intolerance, a short course of eszopiclone during the first two weeks of CPAP treatment may reduce treatment discontinuation $^{55}$. In the presence of nasal congestion, the use of heated humidification and nasal steroid therapy could improve patient comfort and reduce discontinuing therapy as well (Fig. 3). The CPAP adherence and compliance could be improved by telemonitoring, reinforcement calls, and close follow-ups ${ }^{56,57}$. The first follow-up visit is typically recommended 1-2 weeks after therapy initiation. Outcome indicators, including evaluations of the resolution of sleepiness (using the Epworth scale), OSA-specific quality of life measures, patient and spousal satisfaction, avoidance of factors worsening disease, practicing proper sleep hygiene, and weight loss for overweight/obese patients, should be performed at each follow-up visit. Despite the CPAP treatment, some patients complain about persisting sleepiness, which is generally due to non-adherence, associated diseases, and CPAP side effects. 

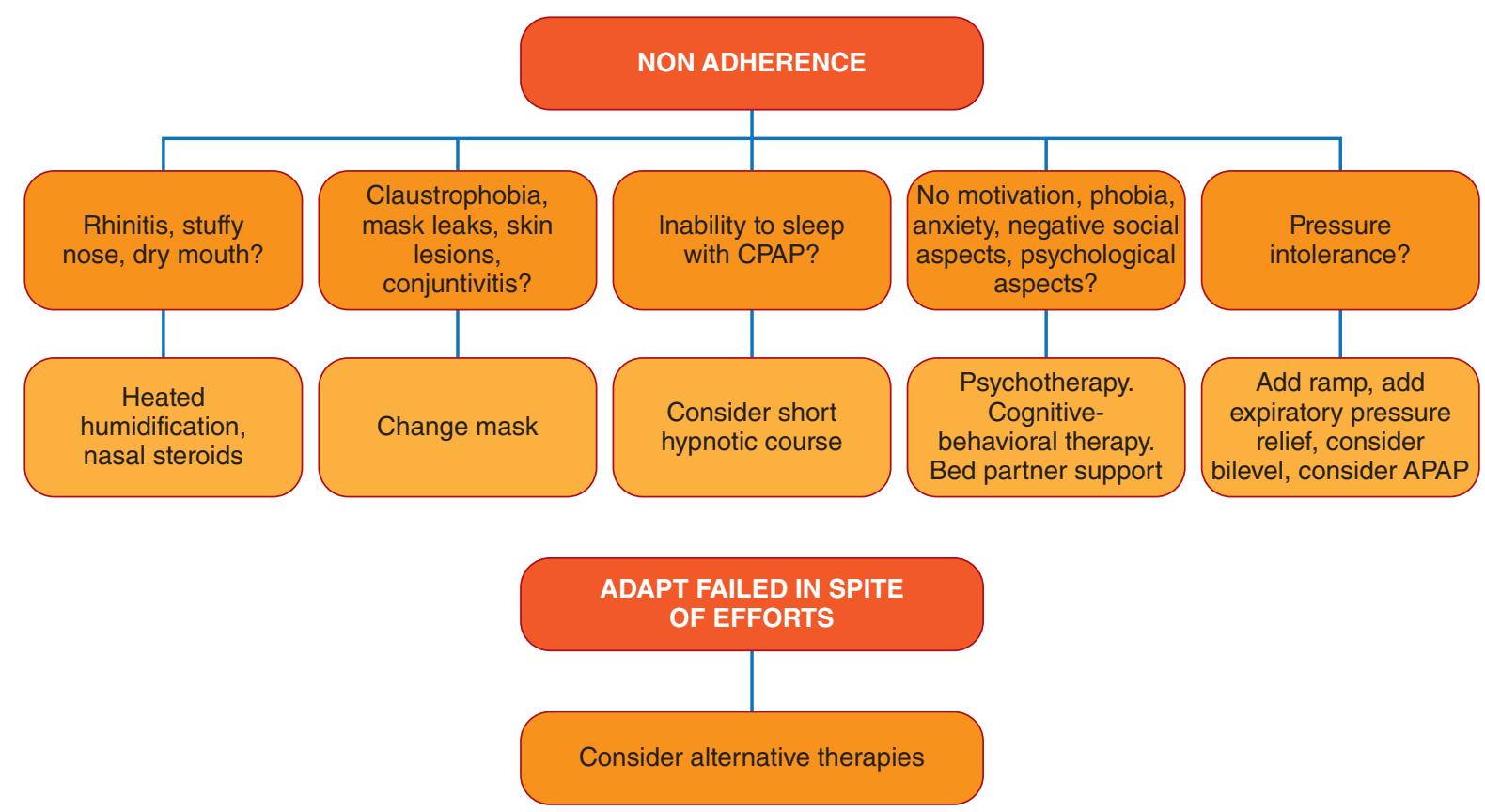

Figure 3. Strategies to improve continuous positive airway pressure adherence.

CPAP: continuous positive airway pressure.

\section{Behavioral treatment: weight loss and positional treatment}

Weight loss should be recommended to all obese patients in conjunction with CPAP therapy. In fact, CPAP treatment has been associated with an increased $\mathrm{BMI}^{58}$. Among obese patients with mild OSA, 60\% were cured through a low-calorie diet and lifestyle chang$\mathrm{es}^{59}$. In moderate-to-severe OSA, weight reduction has been shown to mitigate OSA severity, but without obtaining complete remission ${ }^{60,61}$. All OSA patients should be advised to avoid alcohol and sedatives before bedtime. In most patients, OSA is position-dependent, with the $\mathrm{AHI}$ rate increasing at least twofold in patients sleeping in the supine position compared with the lateral position ${ }^{62}$. Patients with positional OSA have generally mild or moderate sleep apnea syndrome and a lower BMI and are younger ${ }^{63}$. In these patients, positional treatment methods using different devices keeping the patients in a non-supine position are an effective secondary therapy and can also be used as supplementary therapy. A recent study testing the efficacy of a neck-worn vibrating device in mild, moderate, and severe OSA has shown its efficacy in reducing supine sleep time and improving $\mathrm{AHI}^{64}$. Not all patients with positional OSA normalize their AHI when not in the supine position; therefore, a PSG documenting the correction of OSA by position before initiating this treatment (as a first choice) is recommended. 


\section{Oral appliances}

Mandibular advancement devices (MAD) enlarge upper airways and prevent their collapse by holding the lower jaw and tongue in a more anterior position. These devices are indicated as a first choice in patients with mild-to-moderate OSA. As a second line of therapy, such devices could be used in patients who do not tolerate or benefit from CPAP treatment ${ }^{65}$. Several studies have demonstrated improvements in daytime sleepiness and quality of life, as well as an AHI reduction by using MADs. However, the decrease in AHI appears to be lower compared with CPAP. Thus, MADs are not a first-choice treatment for severe OSA ${ }^{66,67}$. Oral appliances should be fitted by qualified dentists experienced in temporomandibular joints, dental occlusion, and OSA management. When used as a primary therapy, a sleep study should be performed to verify the effectiveness of the MAD, and follow-up visits at the dentist are needed to monitor adherence, evaluate improvements in or worsening symptoms, and control device deterioration.

\section{Surgical treatment}

Surgical therapy is rare in OSA treatment. It should be considered as a first option only in patients with mild OSA in which the presence of obstructing anatomy is surgically correctible. As a secondary choice, surgery could be indicated in select patients who do not tolerate CPAP or MADs ${ }^{12}$. Minimally invasive procedures, such as palatal implant and radiofrequency or laser-assisted uvulopalatopharyngoplasty, show mild symptom reductions and a poor decrease in OSA severity and may be offered as a treatment for primary snoring ${ }^{68}$.
Hypoglossal stimulation has been demonstrated as an effective treatment for OSA ${ }^{69}$. However, it is expensive and requires technical and specialized skills. Maxillomandibular advancement and tracheostomy are rarely used techniques.

\section{Future perspectives: combined treatment}

Still largely underutilized, combined treatment might be a future resource for OSA treatment. In mild OSA, for example, lifestyle changes and MADs or postural treatments could control symptoms. Similarly, in patients treated with CPAP, postural treatment and MADs could alternate with CPAP in some specific conditions (e.g. travelling, difficulty adapting to CPAP $)^{70}$. Bariatric surgery associated with CPAP treatment could be considered as a current example of these complementary therapies: weight loss could reduce the pressure requirement, which might improve patient compliance. If weight loss is consistent, CPAP could be substituted with combined alternative therapy.

\section{OBSTRUCTIVE SLEEP APNEA ACROSS GENDER AND AGE: FEMALE AND ELDERLY PATIENTS}

Documented gender differences in the upper airway function and respiratory stability could influence the mechanism involved in the development of OSA. Compared with men, women show thinner oropharyngeal junction, a shorter uvula and reduced upper airway collapsibility. Clinically, OSA is more prevalent in men than in women, and men appear to require higher CPAP pressure than women 
TABLE 2. The 14 golden keys of obstructive sleep apnea

1) OSA is a common disorder that affects $10 \%$ of men and $3 \%$ of women.

2) In women, OSA generally begins during the postmenopausal period, with atypical symptoms and a higher BMI.

3) Obesity is the major risk factor for developing OSA and risk increases as obesity increases.

4) OSA is prevalent among patients suffering from resistant hypertension, type 2 diabetes, congestive heart failure, atrial fibrillation, nocturnal dysrhythmias and stroke.

5) The Berlin and STOP-Bang questionnaires could be used to assess risk of OSA in selected populations.

6) Snoring is the most sensitive symptom of OSA. Nocturnal gasping or choking and witnessed apneas are the most specific symptoms.

7) OSA increases the risk of suffering from arterial hypertension, and, likely, cardiovascular and cerebrovascular diseases.

8) Home testing with portable monitors must to be used to evaluate patients with high or moderate clinical suspicion for OSA and without comorbidities.

9) CPAP prevents upper airways collapse during sleep and improves daytime sleepiness, oxygen desaturation, neurobehavioral performance and quality of life, and it likely reduces cardiovascular risks.

10) In patients with mild or moderate OSA MADs, lifestyle changes and postural treatment should be recommended.

11) An automatic CPAP titration is cost-effective, and it is a good alternative for most patients.

12) Combined treatment (MAD + positional/lifestyle and positional changes) could be a future resource.

13) Given the high prevalence of OSA, general practitioners and nurses should be involved in its management.

14) CPAP compliance is the key issue for obtaining positive outcomes. An adherence rate of $>4$ hours/night is the primary goal.

OSA: obstructive sleep apnea; BMI: body mass index; CPAP: continuous positive airway pressure; MAD: mandibular advancement device.

for a given severity of OSA ${ }^{71}$. These differences in women appear to decrease with ageing. Postmenopausal women are more likely to experience OSA, and women often show atypical symptoms (insomnia and fatigue) and a higher $\mathrm{BMI}^{72}$. Few studies have investigated OSA in women, but the limited data available suggest that OSA could be responsible for worse health consequences in women despite the lower prevalence and decreased severity. Female OSA patients appear to be at a major risk of developing hypertension and endothelial dysfunction, anxiety, and depression and to have increased cardiovascular mortality ${ }^{72,73}$. Adherent CPAP use could reduce these risks. However, specific targeted treatments are needed to improve outcomes in women ${ }^{72}$. In addition, during pregnancy, women experience physiological and hormonal changes related to the airway and lung function (gestational weight gain, pregnancy associated nasopharyngeal edema, decreased functional reserve capacity, and increased arousals from sleep), which increase the likelihood of developing OSA and snoring. There is growing evidence that OSA is associated with adverse pregnancy outcomes, particularly pregnancy induced hypertension and gestational diabetes ${ }^{74}$.

Obstructive sleep apnea prevalence increases with age in both sexes ${ }^{8}$, but most studies of OSA and the associated cardiovascular risk have focused on middle-aged men. Few studies have analyzed the impact of OSA or CPAP treatment exclusively in the elderly, and those that have focused on the elderly have reported contrasting 
results. Some have found an augmented risk of cardiovascular morbidity and mortality due to increased nocturnal blood pressure, cardiovascular events, and arrhythmias ${ }^{6,75}$. Others have not observed increased mortality compared to middle-aged men ${ }^{76}$. Finally, an observational study that monitored a cohort of elderly patients ( $>65$ years old) suspected of having OSA for 10 years has suggested an increased risk of stroke and heart failure in patients with severe OSA not treated with CPAP ${ }^{77}$.

\section{CONCLUSION}

Obstructive sleep apnea is probably a risk factor for cardiovascular diseases. Continuous positive airway pressure treatment is recommended in severe OSA even in the absence of symptoms. In men with severe OSA, CPAP could in fact reduce the risk of fatal and non-fatal cardiovascular events. Most studies have been performed in middle-aged men and additional data are needed to clarify the role of OSA as a risk factor for cardiovascular diseases in women and elderly. Due to its high prevalence, OSA management should imply the involvement of general practitioners (Table 2).

\section{SUPPORT}

Fondo de Investigación Sanitaria (PI10/02763, PI10/02745, PI13/02004 and PI14/01266), the Spanish Respiratory Society (SEPAR), and ALLER.

\section{CONFLICTS OF INTEREST}

None.

\section{REFERENCES}

1. Myers KA, Mrkobrada M, Simel DL. Does this patient have obstructive sleep apnea?: The rational clinical examination systematic review. JAMA. 2013;310:731-41.

2. Terán-Santos J, Jiménez-Gómez A, Cordero-Guevara J. The association between sleep apnea and the risk of traffic accidents. Cooperative Group Burgos-Santander. N Engl J Med. 1999;340:847-51.

3. Barbé F, Pericás J, Muñoz A, et al. Automobile accidents in patients with sleep apnea syndrome. An epidemiological and mechanistic study. Am J Respir Crit Care Med. 1998;158:18-22.

4. Sánchez-de-la-Torre M, Campos-Rodriguez F, Barbé F. Obstructive sleep apnoea and cardiovascular disease. Lancet Respir Med. 2013;1:61-72.

5. Somers VK, Dyken ME, Clary MP, Abboud FM. Sympathetic Neural Mechanisms in Obstructive Sleep Apnea. J Clin Invest. 1995; 96:1897-904.

6. Gottlieb DJ, Yenokyan G, Newman AB, et al. Prospective study of obstructive sleep apnea and incident coronary heart disease and heart failure: the sleep heart health study. Circulation. 2010;122:352-60.

7. Nieto FJ, Peppard PE, Young T, Finn L, Hla KM, Farré R. Sleep-disordered breathing and cancer mortality: results from the Wisconsin Sleep Cohort Study. Am J Respir Crit Care Med. 2012;186:190-4.

8. Peppard PE, Young T, Barnet JH, Palta M, Hagen EW, Hla KM. Increased prevalence of sleep-disordered breathing in adults. Am J Epidemiol 2013;177:1006-14.

9. Eckert DJ, Malhotra A. Pathophysiology of adult obstructive sleep apnea. Proc Am Thorac Soc. 2008;5:144-53.

10. White LH, Bradley TD. Role of nocturnal rostral fluid shift in the pathogenesis of obstructive and central sleep apnoea. J Physiol. 2013;591:1179-93.

11. Sánchez-de-la-Torre M, Campos-Rodriguez F, Barbé F. Obstructive sleep apnoea and cardiovascular disease Lancet Respir Med. 2013;1:61-72.

12. Epstein LJ, Kristo D, Strollo PJ, et al. Adult Obstructive Sleep Apnea Task Force of the American Academy of Sleep Medicine: Clinical guidelines for the evaluation, management and long term care of obstructive sleep apnea in adults. J Clin Sleep Med. 2009;5:263-76.

13. Young T, Peppard PE, Taheri S. Excess weight and sleep-disordered breathing. J Appl Physiol. 2005;99:1592-9.

14. Peppard PE, Young T, Palta M, et al. Longitudinal study of moderate weight change and sleep-disordered breathing. JAMA. 2000;284:3015-21.

15. Sareli AE, Cantor CR, Williams NN, et al. Obstructive sleep apnea in patients undergoing bariatric surgery--a tertiary center experience. Obes Surg. 2011;21:316-27.

16. Kaw R, Pasupuleti V, Walker E, Ramaswamy A, Foldvary-Schafer N. Postoperative complications in patients with obstructive sleep apnea. Chest. 2012;141:436-41.

17. Liao P, Yegneswaran B, Vairavanathan S, et al. Postoperative complications in patients with obstructive sleep apnea: a retrospective matched cohort study. Can J Anaesth. 2009;56:819-28.

18. Martínez-García MA, Capote F, Campos-Rodríguez F, et al. Effect of CPAP on blood pressure in patients with obstructive sleep apnea and resistant hypertension. The HIPARCO Randomized Clinical Trial. JAMA. 2013;310:2407-15.

19. Netzer N, Stoohs RA, Netzer CM. Using the Berlin Questionnaire to identify patients at risk for the sleep apnea syndrome. Ann Intern Med. 1999;131:485-91.

20. Chung F, Subramanyam R, Liao P, et al. High STOP-Bang score indicates a high probability of obstructive sleep apnoea. Br J Anaesth. 2012;108:768-75.

21. Chung F, Yegneswaran B, Liao P. STOP questionnaire: a tool to screen patients for obstructive sleep apnea. Anesthesiology. 2008;108:812-21.

22. Myers KA, Mrkobrada M, Simel DL. Does this patient have obstructive sleep apnea?: The Rational Clinical Examination systematic review. JAMA. 2013;310:731-41.

23. Jacobsen JH, Shi L, Mokhlesi B. Factors associated with excessive daytime sleepiness in patients with severe obstructive sleep apnea. Sleep Breath. 2013;17:629-35. 
24. Kapur VK, Resnick HE, Gottlieb DJ. Sleep disordered breathing and hypertension: does self-reported sleepiness modify the association? Sleep. 2008;31:1127-32.

25. Feng J, He QY, Zhang XL, Chen BY. Epworth Sleepiness Scale may be an indicator for blood pressure profile and prevalence of coronary artery disease and cerebrovascular disease in patients with obstructive sleep apnea. Sleep Breath. 2012;16:31-40.

26. Barcelo A, Barbe F, de la Pena M, et al. Insulin resistance and daytime sleepiness in patients with sleep apnoea. Thorax. 2008;63:946-50.

27. Nena E, Steiropoulos P, Papanas N, et al. Sleepiness as a marker of glucose deregulation in obstructive sleep apnea. Sleep Breath. 2012;16:181-6.

28. Gooneratne NS, Richards KC, Joffe M, et al. Sleep disordered breathing with excessive daytime sleepiness is a risk factor for mortality in older adults. Sleep. 2011;34:435-42.

29. Johns MW. A new method for measuring daytime sleepiness: the Epworth sleepiness scale. Sleep. 1991;14:540-5.

30. Onen F, Moreau T, Gooneratne NS, Petit C, Falissard B, Onen SH. Limits of the Epworth Sleepiness Scale in older adults. Sleep Breath. 2013;17:343-50.

31. Li Y, Zhang J, Lei F, et al. Self-evaluated and close relative-evaluated Epworth. Sleepiness scale vs. multiple sleep latency test in patients with obstructive sleep apnea. J Clin Sleep Med. 2014;10:171-6.

32. Muniesa MJ, Huerva V, Sánchez-de-la-Torre M, Martínez M, Jurjo C, Barbé F. The relationship between floppy eyelid syndrome and obstructive sleep apnoea. Br J Ophthalmol. 2013;97:1387-90.

33. Collop NA, McDowell Anderson W, Boehlecke B, et al. Clinical guidelines for the use of unattended portable monitors in the diagnosis of obstructive sleep apnea in adult patients. Portable Monitoring Task Force of the American Academy of Sleep Medicine. J Clin Sleep Med. 2007;3:737-47.

34. Sánchez-de-la-Torre M, Nadal N, Cortijo A,et al. Role of primary care in the follow-up of patients with obstructive sleep apnoea undergoing CPAP treatment: a randomised controlled trial. Thorax. 2015;70:346-52.

35. Chai-Coetzer L, Antic NA, Sharn Rowlan L. Primary care vs specialist sleep center management of obstructive sleep apnea and daytime sleepiness and quality of life; a randomized trial. JAMA. 2013;309:997-1004.

36. Kushida CA, Littner MR, Hirshkowitz M, et al. Practice parameters for the use of continuous and bilevel positive airway pressure devices to treat adult patients with sleep-related breathing disorders. Sleep. 2006;29:375-80.

37. Gay P, Weaver T, Loube D, Iber C. Evaluation of positive airway pressure treatment for sleep related breathing disorders in adults. Sleep. 2006;29:381-401.

38. Giles TL, Lasserson TJ, Smith BH, White J, Wright J, Cates CJ. Continuous positive airways pressure for obstructive sleep apnoea in adults. Cochrane Database Syst Rev. 2006;3:CD001106.

39. Sharma SK, Agrawal S, Damodaran, et al. CPAP for the metabolic syndrome in patients with obstructive sleep apnea. N Engl J Med. 2011;365:2277-86.

40. Lévy P, Pépin JL, McNicholas WT. Should all sleep apnoea patients be treated? Yes. Sleep Med Rev. 2002;6:17-26.

41. Bratton DJ, Stradling JR, Barbe F, Kohler M. Effect of CPAP on blood pressure in patients with minimally symptomatic obstructive sleep apnoea: a meta-analysis using individual patient data from four randomised controlled trials. Thorax. 2014;69:1128-35.

42. Jaimchariyatam N, Rodriguez CL, Budur K. Does CPAP treatment in mild obstructive sleep apnea affect blood pressure? Sleep Med. 2010;11:837-42.

43. Barbé F, Durán-Cantolla J, Sánchez-de-la-Torre M, et al. Effect of continuous positive airway pressure on the incidence of hypertension and cardiovascular events in non sleepy patients with obstructive sleep apnea: a randomized controlled trial. JAMA. 2012;307:2161-8.

44. Patel SR, White DP, Malhotra A, et al. Continuous positive airway pressure therapy for treating sleepiness in a diverse population with obstructive sleep apnea: results of a meta-analysis. Arch Intern Med. 2003;163:565-71.

45. Weaver TE, Mancini C, Maislin G, et al. Continuous positive airway pressure treatment of sleepy patients with milder obstructive sleep apnea: results of the CPAP Apnea Trial North American Program (CATNAP) randomized clinical trial. Am J Respir Crit Care Med. 2012;186:677-83.

46. Strohl KP, Brown DB, Collop N, et al. ATS Ad Hoc Committee on Sleep Apnea, Sleepiness, and Driving Risk in Noncommercial Drivers. An official
American Thoracic Society Clinical Practice Guideline: sleep apnea, sleepiness, and driving risk in noncommercial drivers. An update of a 1994 Statement. Am J Respir Crit Care Med. 2013;187:1259-66.

47. Marin JM, Carrizo SJ, Vicente E, Agusti AG. Long-term cardiovascular outcomes in men with obstructive sleep apnoea-hypopnoea with or without treatment with continuous positive airway pressure: an observational study. Lancet. 2005;365:1046-53.

48. Vennelle M, White S, Riha RL, et al. Randomized controlled trial of variable-pressure versus fixed-pressure continuous positive airway pressure (CPAP) treatment for patients with obstructive sleep apnea/ hypopnea syndrome (OSAHS). Sleep. 2010;33:267-71.

49. Massie CA, McArdle N, Hart RW, et al. Comparison between automatic and fixed positive airway pressure therapy in the home. Am J Respir Cri Care Med. 2003;167:20-3

50. Ip S, D'Ambrosio C, Patel K, et al. Auto-titrating versus fixed continuous positive airway pressure for the treatment of obstructive sleep apnea: a systematic review with meta-analyses. Syst Rev. 2012;1:20.

51. Kribbs NB, Pack AI, Kline LR, et al. Objective measurement of patterns of nasal CPAP use by patients with obstructive sleep apnea. Am Rev Respir Dis. 1993;147:887-95.

52. Weaver TE, Maislin G, Dinges DF, et al. Relationship between hours of CPAP use and achieving normal levels of sleepiness and daily functioning Proc Am Thorac Soc. 2008;5:173-8.

53. Haentjens P, Van Meerhaeghe A, Moscariello A, et al. The impact of continuous positive airway pressure on blood pressure in patients with obstructive sleep apnea syndrome; evidence from a meta-analysis of placebo-controlled randomized trials Arch Intern Med. 2007;167:757-64.

54. Sawyer AM, Gooneratne N, Marcus CL, Ofer D, Richards KC, Weaver TE. A systematic review of CPAP adherence across age groups: clinical and empiric insights for developing CPAP adherence interventions. Sleep Med Rev. 2011;15:343-56.

55. Lettieri CJ, Shah AA, Holley AB, Kelly WF, Chang AS, Roop SA; CPAP Promotion and Prognosis-The Army Sleep Apnea Program Trial. Effects of a short course of eszopiclone on continuous positive airway pressure adherence: a randomized trial Ann Intern Med. 2009;151:696-702.

56. Chervin RD, Theut S, Bassetti C, Aldrich MS. Compliance with nasal CPAP can be improved by simple interventions. Sleep. 1997;20:284-9.

57. Sparrow D, Aloia M, Demolles DA, Gottlieb DJ. A telemedicine intervention to improve adherence to continuous positive airway pressure: a randomised controlled trial. Thorax. 2010;65:1061-6.

58. Drager LF, Brunoni AR, Jenner R, Lorenzi-Filho G, Benseñor IM, Lotufo PA. Effects of CPAP on body weight in patients with obstructive sleep apnoea: a meta-analysis of randomised trials. Thorax. 2015;70:258-64.

59. Tuomilehto HPI, Seppa JM, Partinen MM, et al. Lifestyle intervention with weight reduction first-line treatment in mild obstructive sleep apnea. Am J Respir Crit Care Med. 2009;179:320-7

60. Johansson K, Neovius M, Lagerros YT, et al. Effect of a very low energy diet on moderate and severe obstructive sleep apnoea in obese men: a randomised controlled trial. BMJ. 2009;339:b4609.

61. Ng SS, Chan RS, Woo J. A randomized controlled study to examine the effect of lifestyle modification program in obstructive sleep apnea Chest. 2015. [Epub ahead of print].

62. Oksenberg A, Silverberg DS, Arons E, Radwan H. Positional vs non positional obstructive sleep apnea patients: anthropomorphic, nocturnal polysomnographic, and multiple sleep latency test data. Chest. 1997;112:629-39.

63. Morgenthaler TI, Kapen S, Lee-Chiong T, et al. Practice parameters for the medical therapy of obstructive sleep apnea. Sleep. 2006;29:1031-5.

64. Levendowski DJ, Seagraves S, Popovic D. Assessment of a neck-based treatment and monitoring device for positional obstructive sleep apnea. J Clin Sleep Med. 2014;10:863-71.

65. Andren A, Hedberg P, Walker-Engstrom ML, Wahlen P, Tegelberg A. Effects of treatment with oral appliance on 24-h blood pressure in patients with obstructive sleep apnea and hypertension: a randomized clinical trial. Sleep Breath. 2013;17:705-12. 
66. Gotsopoulos H, Chen C, Qian J, Cistulli PA. Oral appliance therapy improves symptoms in obstructive sleep apnea: a randomized, controlled trial. Am J Respir Crit Care Med. 2002;166:743-8.

67. Phillips CL, Grunstein RR, Darendeliler MA, et al. Health outcomes of CPAP versus oral appliance treatment for obstructive sleep apnea: a randomized controlled trial. Am J Respir Crit Care Med. 2013;187:879-87.

68. Aurora RN, Casey KR, Kristo D, et al. Practice parameters for the surgical modifications of the upper airway for obstructive sleep apnea in adults. Sleep. 2010;33:1408-13.

69. Van de Heyning PH, Badr MS, Baskin JZ, et al. Implanted upper airway stimulation device for obstructive sleep apnea. Laryngoscope. 2012;122:1626-33.

70. El-Solh AA, Moitheennazima B, Akinnusi ME, Churder PM, Lafornara AM. Combined oral appliance and positive airway pressure therapy for obstructive sleep apnea: a pilot study Sleep Breath. 2011;15:203-8.

71. Li Z, Li Y, Yang L, et al. Characterization of obstructive sleep apnea in patients with insomnia across gender and age. Sleep Breath. 2015;19:723-7.

72. Won C, Guilleminault C. Gender differences in sleep disordered breathing: implications for therapy. Expert Rev Respir Med. 2015;9:221-31.
73. Campos-Rodriguez F, Martinez-Garcia MA, De la Cruz-Moron I, et al Cardiovascular mortality in women with obstructive sleep apnea with or without continuous positive airway pressure treatment: A Cohort Study. Ann Intern Med. 2012;156:115-22.

74. Pamidi S, Pinto LM, Marc I, Benedetti A, Schwartzman K, Kimoff RJ. Maternal sleep-disordered breathing and adverse pregnancy outcomes: a systematic review and metaanalysis. Am J Obstet Gynecol. 2014;210:52. e1-52.e14.

75. Mehra R, Stone KL, Varosy PD, et al. Nocturnal arrhythmias across a spectrum of obstructive and central sleep-disordered breathing in older men: outcomes of sleep disorders in older men (MrOS sleep) study. Arch Intern Med. 2009;169:1147-55.

76. Lavie P, Lavie L. Unexpected survival advantage in elderly people with moderate sleep apnea. J Sleep Res. 2009;18:397-403.

77. Martínez-García MA, Campos-Rodríguez F, Catalán-Serra P. Cardiovascular mortality in obstructive sleep apnea in the elderly: role of long-term continuous positive airway pressure treatment. A prospective observational study. Am J Respir Crit Care Med. 2012;186:909-16.

\section{Appendix 1. The Berlin Questionnaire}

\section{CATEGORY 1}
1. Do you snore?
a. Yes
b. No
c. Don't know

If you snore:
2. Your snoring is:
a. Slightly louder than breathing
b. As loud as talking
c. Louder than talking
d. Very loud - can be heard in adjacent rooms

\section{How often do you snore? \\ a. Nearly every day \\ b. 3-4 times a week \\ c. 1-2 times a week \\ d. 1-2 times a month \\ e. Never or nearly never}

4. Has your snoring ever bothered other people?
a. Yes
b. No
c. Don't Know

5. Has anyone noticed that you quit breathing during your sleep?

a. Nearly every day

b. 3-4 times a week

c. 1-2 times a week

d. 1-2 times a month

e. Never or nearly never

\section{CATEGORY 2}

6. How often do you feel tired or fatigued after your sleep?

a. Nearly every day

b. 3-4 times a week

c. 1-2 times a week

d. 1-2 times a month

e. Never or nearly never

7. During your waking time, do you feel tired, fatigued or not up to par?

a. Nearly every day

b. 3-4 times a week

c. 1-2 times a week

d. 1-2 times a month

e. Never or nearly never

8. Have you ever nodded off or fallen asleep while driving a vehicle?

a. Yes

b. No

If yes: 9 . How often does this occur?

a. Nearly every day

b. 3-4 times a week

c. 1-2 times a week

d. 1-2 times a month

e. Never or nearly never

\section{CATEGORY 3}

10. Do you have high blood pressure?

- Yes

- No

- Don't know 


\section{APPENDIX 2. THE STOP-Bang questionnaire}

S Do you snore loudly (louder than talking or loud enough to be heard through closed doors)?

T Do you often feel tired, fatigued, or sleepy during daytime?

0 Has anyone observed you stop breathing during your sleep?

$P$ Do you have or are you being treated for high blood pressure?

B BMI more than $35 \mathrm{~kg} / \mathrm{m} 2$ ?

A Age over 50 years old?

N Neck circumference greater than $40 \mathrm{~cm}$ ?

G Gender male?

High risk of OSA: answering yes to three or more items.

\section{Appendix 3. The Epworth Sleepiness Scale}

How likely are you to doze off or fall asleep in the following situations, in contrast to feeling just tired? This refers to your usual way of life in recent times. Even if you have not done some of these things recently, try to work out how they would have affected you. Use the following scale to choose the most appropriate number for each situation:

$0=$ would never doze; 1 = slight chance of dozing; $2=$ moderate chance of dozing; 3 = high chance of dozing.

Sitting and reading

Watching television

Sitting inactive in a public place (e.g. a theater or meeting)

As a passenger in a car for an hour without a break

Lying down to rest in the afternoon when circumstances permit

Sitting and talking to someone

Sitting quietly after a lunch without alcohol

In a car, while stopped for a few minutes in the traffic

TOTAL SCORE

SCORE RESULTS: 1-6: Congratulations, you are not sleepy

7-8: Your score is average

9 and up: Very sleepy and should seek medical advice

Adapted from Johns, et al..29. 
